See discussions, stats, and author profiles for this publication at: https://www.researchgate.net/publication/318187406

\title{
Modelling the demand for inbound medical tourism: The case of Malaysia
}

Article in International Journal of Tourism Research · July 2017

DOI: 10.1002/jtr.2131

2 authors: 


\title{
Modelling the demand for inbound medical tourism: The case of Malaysia
}

\author{
Chor Foon Tang ${ }^{1}$ (D) I Evan Lau ${ }^{2}$
}

${ }^{1}$ Centre for Policy Research and International Studies, Universiti Sains Malaysia, Penang, Malaysia

${ }^{2}$ Centre for Business, Economics and Finance Forecasting (BEFfore), Faculty of Economics and Business, Universiti Malaysia Sarawak, Kota Samarahan, Sarawak, Malaysia

Correspondence

Chor Foon Tang, Centre for Policy Research and International Studies, Universiti Sains Malaysia, 11800 USM, Penang, Malaysia. Email: tcfoon@usm.my; tcfoon@gmail.com

\section{Funding information}

Geran Penyelidikan Khas (Top Down), Universiti Malaysia Sarawak, Grant/Award Number: 03(TD04)/1054/2013(02)

JEL Classification: C32

\begin{abstract}
This paper empirically examines the macroeconomic determinants for medical tourism demand using time series econometrics methodology. We find that income, price, exchange rate, SARS outbreak, safety, medical quality, manpower, and medical facilities are significantly affecting the long-run demand behaviour of medical tourism in Malaysia. In order to attract medical tourists, policymakers in Malaysia should (a) reduce the medical prices, (b) reduce the crime rate and improve safety, and (c) continue the improvement of research, medical quality, manpower, and facilities to support the revolution of inbound medical tourism demand in Malaysia. This is to ensure the Malaysia's sustainable economic development.
\end{abstract}

\section{KEYWORDS}

cointegration, forecasts, Malaysia, medical tourism demand

\section{1 | INTRODUCTION}

It has been widely recognised that tourism is a vital and dynamic economic sector that contributes significantly to economic growth of a country by stimulating its market demand (Brida, Cortes-Jimenez, \& Pulina, 2016; Brida, Lanzilotta, Pereyra, \& Pizzolon, 2015; Tang \& Tan, 2015). In the light of this, apart from agriculture, manufacturing, and the inflows of foreign capital, tourism has been ascertained to be an effective catalyst of growth to accelerate the process to become a developed nation. Therefore, many developing countries including Malaysia are heading toward positioning themselves as attractive tourism destinations. Historically, tourism is nothing more than leisure activities, and thus, travelling abroad is only for the purpose of leisure (Vanhove, 2011). Due to its dynamic expansion, the tourism sector nowadays covers not only the aspect of leisure but also those of sport, education, environment, medical, and others. "Medical" is one of the key aspects in the tourism sector that is generating a lucrative income to the recipient country (Chaynee, 2003; Wong \& Musa, 2012; Tang, 2015). This aspect of tourism is also known as health or medical tourism. Connell (2011, 2013) narrated that medical tourism is a late 20th century phenomenon that has boomed since then. This new niche emerged as an important industry at present where people travel abroad to obtain medical, dental, and surgical care (Connell, 2006).
Tourism is a significant contributor to Malaysia's gross domestic product and has been identified as one of the 12 National Key Economic Areas under the Economic Transformation Programme (PEMANDU, 2014). Since the establishment of the Tourism Development Corporation in 1972, a range of national government agencies and policy initiatives have sought to stimulate and promote Malaysia as an international tourism destination. By 2014, the tourism sector was the sixth highest contributor to the Malaysian gross domestic product. In the same year, the tourist arrivals grew by $6.7 \%$ to 27.4 million visitors, and receipts were RM72 billion compared to RM65.4 billion in 2013 (PEMANDU, 2014). Health care is also a part of National Key Economic Area's initiative that has seen robust growth over the past decade, and this sector has one of the highest multipliers in the economy (PEMANDU, 2014). With the integration of these 2 key areas, medical tourism is becoming an important niche sector in Malaysia. ${ }^{1}$ In recent study, Tang and Abdullah (2016) estimated a growth model for Malaysia by accommodating medical tourism as an additional determinant of growth. The study revealed that medical tourism is not only stimulating economic growth in Malaysia but is also

${ }^{1}$ Chee (2010) indicated that Malaysia is among one of the countries in the region that is actively promoting medical tourism as the progression from the preceding period of privatisation and corporatisation of health care. 